\title{
EXPLAINING URBAN-RURAL VARIATIONS IN HEALTH: A REVIEW OF INTERACTIONS BETWEEN INDIVIDUAL AND ENVIRONMENT
}

\author{
ROBERT A. VERHEIJ \\ Netherlands Institute of Primary Health Care, PO Box 1568, 3500 BN Utrecht, The Netherlands
}

\begin{abstract}
In order to gain insight into the relation between health and people's environment, literature published between 1985 and 1994 was gathered from several international databases. An introduction into existing theory regarding geographic disparities is presented: geographical drift and breeder hypotheses are discussed. This is followed by a critical review focusing on interaction effects of urbanicity and individual characteristics on health. This leads to two major conclusions. First, emphasis in past research has been primarily on urban constraints rather than opportunities. Positive aspects of urban living are often insufficiently appreciated. Second, positive and negative environmental aspects have an effect on health that is often dependent on individual characteristics. The extent to which the environment exerts influence on a person's health is dependent on that person's individual characteristics. These conclusions are relevant only for further developing the breeder hypothesis, however. Large scale individual based longitudinal data should be studied in order to gain more insight into the relative importance of the geographical drift hypothesis.
\end{abstract}

Key words--urbanization, mental health, well-being, perceived health

\section{INTRODUCTION}

Health is believed to be influenced by both ecological (aggregate) as well as individual characteristics, yet much large scale sociological and geographic research focuses on either the individual or his environment. Until recently the division between these two levels was unsurmountable because of methodological statistical problems. With the increasing use of multilevel modelling techniques into health research, however, it has become possible to do justice to this basic understanding. Individual and environmental determinants of health can be studied simultaneously [1]. Multilevel modelling is a relatively new technique that provides some new possibilities for exploration of human-environment relations. The theoretical bases for multilevel modelling are still being formulated. We begin by critically reviewing recent research in a quest for answers to the question: What is the role of the environment in explaining the health of individuals?

The environmental characteristic that is central in this paper is urbanicity, which is meant to indicate the extent to which a place is urban or rural. It should not be confused with urbanization which refers to the process of a place becoming urban. While urbanization is still a major concern in developing countries, in the Western world urbanicity is more important. For example, the weighted average annual growth rate of urban population in OECD countries between 1980 and 1991 was $0.8 \%$, while the comparable figure for 'low and middle income economies' was $6.3 \%$. On the other hand, the 1991 weighted average urban population was $77 \%$ in OECD countries and $46 \%$ in low and middle income countries. In this paper we will concentrate on urbanicity in OECD countries [2].

There are two interconnected reasons for focusing on urbanicity: the popularity of the subject, combined with the lack of understanding of its impact on health. First, urbanicity constitutes indeed one of the most often employed environmental features in health research. In many cases it is in fact the only ecological variable that is taken into account and usually is the only ecological variable that does have, at least to some extent, a universal meaning (contrary to, for instance, the variable 'region'). Furthermore, popularity of the concept of urbanicity can be illustrated by the fact that the World Health Organization (WHO) has been developing a Healthy Cities Project that aims at improving the health of urban residents. A large number of European cities are today participating in this project. Within this project a socioecological model of health is fundamental $[3,4]$. As yet, however, insight into the mechanisms behind this ecological approach is lacking and, moreover, it is unclear if urban residents are indeed less healthy than others.

This leads us to the second reason for focusing on urbanicity: the vagueness of the concept. As Hoggart [5] writes: "I do not mean (. .) that there are no differences between (most) rural and urban places, but rather that in the main these are generated by the uneven presence of some known causal factor ' $X$ ', as 
opposed to either rurality or urbanity. The obvious follow-up point is that for theory to progress we should focus on ' $X$ "' (p. 251). A similar point is made by Webb [6]: "as far as the differential prevalence of mental disorder is concerned, the rural-urban variable has little utility", and "Rather the area being studied must be defined in terms of more relevant criteria, especially the detailed composition of the population". In other words, we should concentrate on the content of the concept of urbanicity. Later on it will be shown that this is more than just the composition of the population. In order to gain more insight into the content of urbanicity we will emphasize the relation between individual and environment.

We begin with a short description of the methodology, followed by an introduction to the existing theory of spatial variations in health. In the latter, the relevance of interaction effects is also explained. We then examine the literature on mental health, well-being, and physical health, followed by a discussion of the more important findings and their implications for the present research.

\section{METHODS}

For our purposes, a distinction is made between three aspects of health: mental health, physical health, and 'well-being'. A discussion of whether health is the absence of illness, or something else, is beyond the scope of this article. Well-being is regarded as a combination of the absence of physical as well as mental problems. Literature published after 1985 was gathered from various international data bases, such as Medline, PsychLit, Sociofile, Econlit, SCI and GSI, using the keywords morbidity and epidemiology together with the keywords urban and rural. We also searched the catalogue of the Netherlands Institute of Primary Health Care (NIVEL). This search produced a large number of studies in which comparisons are made between urban and rural health. In the interest of space limitations, literature dealing with either urban or rural health was not included, even though a comparison of these studies are in themselves interesting. We limited our review to papers that deal with explicit studies of interaction effects. We also excluded studies on mortality and research from other than OECD countries. The reason for limiting our search to these nations is that there is at least some common agreement among them of what constitutes an urban or rural area. Even though cities like Amsterdam and New York are different in many respects, they share a high level of economic development (which is one of the principal determinants of health). For recent reviews of the relationship between urbanization and health in developing countries, the reader is referred to Marsella [7] and Harpham [8].

\section{THEORETICAL FRAMEWORK}

Before presenting a review of the literature on the relation between urbanicity and health, a brief introduction is made to possible mechanisms behind spatial variations in health: the breeder and drift hypotheses (Table 1).

Behind the drift hypothesis (see for example Lewis et al. [9]) there is a notion of selection processes that result in a higher concentration of either ill people (direct selection) or in a spatial concentration of more susceptible persons (indirect selection). Direct selection may take place because healthy people stay and ill people move, or the other way around. Indirect selection takes place if people with certain health related characteristics move to or from specific places. An empirical confirmation of the drift hypothesis would be that urban/rural differences would not persist when accurate measures of past and present illness, together with past and present other individual determinants of health are included in analytic models.

It is not surprising that very little is known about the importance of direct and indirect selection. In order to investigate direct selection effects longitudinal data are needed about large numbers of individuals, including mobility and (past) illness behaviour. Only seldom (if ever) are these demands met. Pre-1985 literature, such as reviewed in Jones and Moon [10, Chap. 5], often has the additional problem of being based on aggregate data. Although more often based on individual data, recent studies still have a cross-sectional design, and no study contains detailed variables on spatial mobility or on past illness, making it virtually impossible to detect selection effects if they are present.

Two studies were found in which an attempt was made to control for selection effects (within a crosssectional design). Both of these tend to reject the drift hypothesis. In Blazer et al. [9], evidence is found against the drift hypothesis, as far as depressive symptomatology is concerned. They tried to get a

Table 1. Four mechanisms to account for geographical variations in health

\begin{tabular}{ll}
\hline $\begin{array}{l}\text { Breeder hypothesis: } \\
\text { spacial concentration of illness caused by: }\end{array}$ & $\begin{array}{l}\text { Drift hypothesis: } \\
\text { spatial concentration of illness caused by: }\end{array}$ \\
\hline $\begin{array}{l}\text { spatial variations in exposure to environmental factors } \\
\text { (e.g. pollution, traffic, housing quality) }\end{array}$ & $\begin{array}{c}\text { direct selection: ill people move to (or from) specific } \\
\text { environments or remain in these environments }\end{array}$ \\
$\begin{array}{l}\text { spatial variations in behaviour (e.g. drug/alcohol abuse, } \\
\text { physical exercise, church attendance) }\end{array}$ & $\begin{array}{c}\text { indirect selection: susceptible persons move to (or from) } \\
\text { specific environments or remain here }\end{array}$ \\
\hline
\end{tabular}


grip on migration by asking respondents whether they had moved in the last 5 years. "When moving within the last five years is controlled (. .), the urban/rural effect remains" (p. 655). Another attempt is provided by Lewis et al. [11], who employed a model including cannabis use, parental divorce, and family history of psychiatric disorder, and concluded that being raised in a city increased the odds of becoming a schizophrenic by $57 \%$, thereby giving support to the breeder hypothesis.

However, the study by Blazer et al. [9] provides only circumstantial evidence against (in)direct selection, because no information is included concerning the respondent's personal and illness characteristics before migrating. Furthermore, they do not take account of the fact that a relatively large part of all migration takes place within cities. The study by Lewis suffers from the fact that no comparison is made between the influence of place of upbringing and place of residence (which is probably the same in many cases). Large scale longitudinal studies are necessary to test the drift hypothesis but have yet to take place.

Behind the breeder hypothesis again two mechanisms may be at work. First, there may be certain environmental factors to which people are directly exposed. Obvious examples of the physical environment are the negative externalities of nuclear plants, high traffic densities, high levels of noise and pollution. Also, the social environment may be important: exposure to activities of other persons that are specific to certain environments. For example, high levels of social support are often thought to be a particular aspect of rural areas. Exposure to stress is another important example of the breeder hypothesis. The stress-hypothesis [7] that is frequently used to explain urban-rural differences in mental health and well-being can be regarded as another example of exposure. According to this hypothesis urban residents are more frequently and more severely confronted with stressors than rural residents, resulting in higher levels of psychiatric morbidity.

The second mechanism is associated with certain types of illness-related behaviour. Smoking, drinking and substance abuse are examples of health behaviour that is (somewhat) more common in urban residents [12]. The distinction between exposure and behaviour is somewhat artificial since one part of the population may be exposed to the behaviour of another part (e.g. passive smoking, unsafe driving, crowded housing). A combination of both mechanisms is evident in the stress-hypothesis: stress can be attributed to one's own behaviour, but also to exposure to the behaviour of others.

According to Marsella [7], studying urban-rural differences alone does not materially advance our knowledge and future research should focus on specific sub-populations. To appreciate this, one only has to realize that most environments have positive and negative qualities but that these qualities are not experienced equally by all residents. For some categories of people the positive sides may prevail, while for others the negative sides are more important. Some environments may, for instance, be characterized as 'tolerant', but this is only beneficial to those who deviate from what is normal. Good air quality may serve as another example. It was observed by Jones et al. [13] that the lung capacity of non-smokers was negatively related to the urbanicity of residence, while such negative relationship was absent in smokers. While showing the importance of looking at sub-populations, these examples also demonstrate that the importance of sub-populations will only appear by contrasting such populations. Sub-populations should be compared with other subpopulations. Therefore, the remainder of this paper will be primarily concerned with interaction effects found in the literature.

\section{MENTAL HEALTH}

There is an abundance of literature on the relationship between mental health and urbanicity. The literature discussed here is not a complete review, but it provides insight into the current understanding of urban-rural variations in mental health. For this review we attempted to find all post-1985 literature that involved screening instruments like GHQ and CES-D, and the more symptom-oriented approach of DSM-III and PSE.

Very little attention will be paid to the incidence of specific diagnoses. The reason for this is that most of these studies deal with so-called 'revealed incidence', inevitably mixing utilization and health. Especially milder forms of psychiatric morbidity will often remain undetected, and because of geographical differences in provision of health care, this omission will not be equally distributed over space.

Though some attention will be paid to studies that deal with aggregate data, the larger part of the literature discussed below builds on individual data. First, the main determinants of mental illness used in empirical studies will be discussed. Second, the emphasis will be on interaction effects between these determinants and urbanicity. Table 2 gives an overview of findings from studies in which significant interaction effects were found. This table shows the most important individual determinants of mental illness. It has long been recognized that mental illness is to some extent associated with demographic variables like age and gender, as well as socioeconomic variables. It is not surprising to find that such variables are most commonly taken into account. Differences exist concerning the inclusion of race, health behaviour, social support variables and mobility measures. Race is included only in studies in which there is a substantial amount of variation in race, which is usually not the case in European studies. Among measures of health behaviour drinking seems to matter [14]. Social support variables 
Table 2. Urbanicity and mental health: main effects and interactions with urbanicity found in empirical research after 1985

\begin{tabular}{|c|c|c|c|c|c|}
\hline Source & Country & Health measure & Model main effects & $\begin{array}{l}\text { Interaction urbanicity } \\
\text { with }\end{array}$ & $\begin{array}{l}\text { Mechanism behind } \\
\text { interaction effect }\end{array}$ \\
\hline$[17]$ & US & depression (CES-D) & $\begin{array}{l}\text { age, gender, race, income, } \\
\text { education, marital status, } \\
\text { length of residence }\end{array}$ & race & $\begin{array}{l}\text { fewer opportunities in } \\
\text { rural areas and in } \\
\text { black people } \rightarrow \text { learned } \\
\text { helplessness, especially in } \\
\text { rural black people } \rightarrow \\
\text { depression }\end{array}$ \\
\hline [30] & US & depression (CES-D) & $\begin{array}{l}\text { age, gender, race, } \\
\text { unemployment, } \\
\text { family status, education, } \\
\text { income, urbanicity }\end{array}$ & $\begin{array}{l}\text { race, gender, family status, } \\
\text { race/gender, gender/family } \\
\text { status }\end{array}$ & $\begin{array}{l}\text { ghettos relatively } \\
\text { unhealthy }\end{array}$ \\
\hline [22] & GB & $\begin{array}{l}\text { psychiatric caseness } \\
\text { (GHQ) }\end{array}$ & $\begin{array}{l}\text { gender, unemployment, } \\
\text { urbanicity }\end{array}$ & unemployment & $\begin{array}{l}\text { more social support and } \\
\text { informal employment in } \\
\text { rural }\end{array}$ \\
\hline [23] & NL & $\begin{array}{l}\text { depressive symptoms } \\
\text { (self reported) }\end{array}$ & $\begin{array}{l}\text { demographic-, financial-, } \\
\text { network variables, } \\
\text { type of worries, } \\
\text { aspects of unemployment }\end{array}$ & $\begin{array}{l}\text { duration of unemployment, } \\
\text { type of financial worries }\end{array}$ & $\begin{array}{l}\text { more stigmatization in } \\
\text { rural }\end{array}$ \\
\hline [14] & US & depression (CES-D) & $\begin{array}{l}\text { gender, age, race, income, } \\
\text { education, marital status, } \\
\text { religious commitment, } \\
\text { drinking behaviour }\end{array}$ & $\begin{array}{l}\text { life changes/drinking } \\
\text { behaviour }\end{array}$ & not given \\
\hline [15] & NZ & $\begin{array}{l}\text { psychiatric caseness } \\
\text { (PSE/GHQ) }\end{array}$ & $\begin{array}{l}\text { age, gender, SES, } \\
\text { unemployment, } \\
\text { social networks, } \\
\text { past sexual abuse }\end{array}$ & $\begin{array}{l}\text { age, marital satus, } \\
\text { unemployment }\end{array}$ & $\begin{array}{l}\text { social buffering in rural, } \\
\text { tolerance in urban }\end{array}$ \\
\hline [16] & US & $\begin{array}{l}\text { major depression } \\
\text { (DIS/DSM-III) }\end{array}$ & $\begin{array}{l}\text { age, gender, race, SES, } \\
\text { family status, } \\
\text { social network variables, } \\
\text { mover, urbanicity }\end{array}$ & age & $\begin{array}{l}\text { social change more } \\
\text { negative effects in } \\
\text { young people in } \\
\text { urban areas }\end{array}$ \\
\hline [25] & US & somatization (DIS) & $\begin{array}{l}\text { age, gender, race, educa- } \\
\text { tion, marital status, health } \\
\text { care utilization, urbanicity }\end{array}$ & gender, education & $\begin{array}{l}\text { more role conflicts in } \\
\text { urban females }\end{array}$ \\
\hline [27] & US & $\begin{array}{l}\text { existence of mental } \\
\text { health problems }\end{array}$ & $\begin{array}{l}\text { gender, age, stressful life } \\
\text { events, urbanicity }\end{array}$ & $\begin{array}{l}\text { type of stressful life } \\
\text { events }\end{array}$ & not given \\
\hline
\end{tabular}

may concern the "availability and adequacy of social integration and attachment" [15], but also more simple measures like the availability of a confidant [16]. Mobility is usually measured by asking whether or not one has recently moved (see, for example $[9,17])$.

It is often found that urban residents are in worse mental shape. There are many exceptions, however. A Finnish study by Joukamaa et al. [18] found no effect of urbanicity on mental health. Reitzes et al. [19] found no direct effect or urbanicity on mental health in an elderly population, controlling for personal and social characteristics, network and activity variables (interaction effects found by these authors will be discussed below). Also, among children in Sweden no urbanicity-effect was found regarding depressive symptoms [20]. Another study involving New Zealand women failed to show any urban/rural differences in mental health [15]. The oft-cited conclusion drawn by Dohrenwend and Dohrenwend [21] that the level of mental problems is on the whole higher in urban areas can not be maintained on the basis of recent literature.

-besides these main effects, interaction effects were observed between urbanicity and race, gender, education, unemployment, marital status, physical health, occurrence of stressful life events, and drinking behaviour. These will be discussed below.

Neff and Husaini [17] found an urbanicity-race interaction effect on depression (CES-D). Black respondents had higher levels of depressive symptoms overall and less positive affect than white participants, though only in the rural sample, while race differences in positive affect were absent in the urban sample. "Race differences were largely specific to the rural sample, and urban-rural differences were largely specific to black participants" [17], (p. 531). Neff and Husaini challenged the stress-hypothesis and state that besides more stress and disorganisation, the city also provides more freedom and other opportunities. They suggest a 'learned helplessness' hypothesis that states that the rural lack of opportunities and lacka of freedom stimulates helplessness and thereby depression. A similar causation is followed to account for race differences. Black persons experience fewer opportunities than white persons, so that negative stimuli are concentrated in black urban persons, explaining the relatively high depression scores of black rural residents. Although Neff and Husaini offer the valuable insight that urban stress may be counterbalanced by urban opportunities, the 
question of which of these prevails in which cases remains to be answered.

The relationships described above were only found for depressions, not for general well-being and physiological symptoms. Assuming that both depression and low well-being are caused by stress, the authors make a distinction between acute and chronic stressors. Depressive symptoms are in their view caused by chronic stressors (such as caused by living in a ghetto) and general well-being is mostly influenced by acute stressors (transient life events), which are more evenly distributed among urbanicity/race categories. Although not specifically linked to one type of disorder, this distinction is also made by Harpham [8]. On the basis of such suggestions it is clear that future research into urban-rural variations should benefit from the inclusion of explicit stress measures and that a distinction between chronic and acute stressors might be useful. One of these stressors is unemployment.

Also, the relation between unemployment and the incidence of depression has been found to vary according to urbanicity [22]. Contrary to what might have been expected, Harding and Sewel [22] found that unemployment among urban men has a more negative effect on mental health than among rural men. Two possible explanations are offered. First, there may be a higher level of social support in the rural area that counteracts the negative effects of unemployment. Second, the distinction between employment and unemployment may be sharper in urban areas than in rural areas. In the particular research-setting, rural areas, may have more opportunities for informal employment, which may dampen the effects of formal unemployment.

It was hypothesized by Leeflang et al. [23] that the influence of unemployment on general health would differ from urban to rural areas. This, generally speaking, appeared not to be the case in their study: "interaction effects were found in none of the demographic variables, so we can assume that existing differences between employed and unemployed are the same in the rural and in the urban area" (p. 345). However, the power of certain variables in explaining depressive symptoms did differ from urban to rural areas. In rural areas these symptoms were to a higher extent dependent on not being able to provide for dwelling costs and to a lesser extent on the duration of the unemployment.

Besides demographic and socio-economic characteristics the effect of certain types of health behaviour may vary between urban and rural areas. Neff and Husaini [14] concentrated on the urban-rural differences in the effects of alcohol consumption on depressions. The buffering effect of alcohol consumption on the relationship between depression and life events appeared only to be significant in rural areas. Translating this into a causal relationship would mean that drinking helps against depressions, but only in the countryside. An explanation for this is not offered by Neff and Husaini. However, Tousignant and Kovess [24] in their study among urban and rural alcoholics found that borderline personality traits were found only among the urban samples, which led them to conclude that alcoholism is better tolerated in rural areas and, therefore, drinkers are not pushed into deviant behaviour. A possible side effect may be that the presumed depression-buffering effect of alcoholism is more prevalent in rural communities.

Romans-Clarkson et al. [15] also find interesting interactions: age and unmarried were found to be associated with psychiatric problems in urban but not in rural women. Urban elderly women and rural divorced and separated women were more likely to exhibit psychiatric disorders than other women. According to the authors, elderly women find it easier to cope with travails in a rural environment. An urban environment tends to be more tolerant of a variety of behaviours.

Crowell et al. [16] found an association between urbanicity and age. Younger residents in urban areas appeared to be at greater risk for major depression, while in rural areas it was the older residents who were at greater risk, controlling for the other independent variables. Apparently the depression buffering quality of rural areas and the depression enhancing quality of urban areas is something that mostly affects younger people. This may be related to the possibility that social change in general is experienced first and most rapidly in urban areas, particularly by young adults. If the rural-buffer hypothesis is correct, their rural counterparts would be less prone to depression.

Research by Swartz et al. [25] indicates that the effects of urban residence on somatization differs by gender and education. They measured somatization with the Diagnostic Interview Schedule, which indicates the extent to which people tend to translate psychiatric problems into somatic problems. In rural areas, somatization decreases with education. In urban areas this relationship is almost absent. According to the authors education was less effective in reducing somatization in urban areas. Apparently there are environmental pressures on more highly educated urban respondents that counteract the effect of education [25] (p. 51). Urban women exhibit more somatization symptoms than rural women. As the authors interpret this it may be due to the possibility that urban women experience more role conflicts. Why these mechanisms would trigger more somatization (instead of direct psychiatric complaints) remains unclear.

Yet another urbanicity-education interaction was found by Carpiniello et al. [26]. Less educated elderly women living in urban areas were especially more often depressed than their rural counterparts. The authors see this result as confirming the urban stress hypothesis. Even with respect to the impact of stressful life events it seems to make a difference whether women live in an urban or a rural community [27]. 
In a rural sample of women the total number of stressful events was an indicator of mental health problems, while in the urban sample this was replaced by the number of negative stressful life events. An explanation for this intriguing result is not offered.

\section{Well-being}

It is of course hard, if not impossible, to give an objective definition of well-being. We use the term here only as a means to group and discuss jointly those studies that have some health measure that is self assessed and does not directly refer to either mental or physical health. Such health measures may be referred to as happiness, life satisfaction, or well-being. Again we will first pay some attention to the main determinants before turning to interaction effects with urbanicity.

It is not surprising to also find evidence of effects of demographic and socio-economic variables. Considering our definition of well being it is also not surprising to find that health statis plays an important explanatory role. Social network variables are also sometimes included $[19,28]$. Health behaviour variables, such as drinking, smoking, etc., are usually not considered to relate to well being. Some puzzling interaction effects and the possible mechanisms behind them will be discussed below.

Palisi et al. [29] report on health-urbanicity relations involving race. They find a consistent negative relation between urbanicity and happiness among white people, but no significant relation among black people (though this may also be due to smaller numbers). They come up with a relative deprivation hypothesis according to which people tend to judge their happiness by comparing it with others in their vicinity (and of their own colour). Though black people in urban areas usually live in unhealthy ghetto-like neighbourhoods, they will not regard themselves very unhappy, because their neighbours and friends live in the same circumstances. The reverse would then be true for urban white persons, who live more dispersed. A study conducted among poor Americans, however, reports that poor black Americans are happier in rural areas, while poor white Americans are happier in urban areas [30].

In yet another study urbanicity-race interaction effects on well-being were absent. Neff and Husaini [17] did not find any urbanicity-race interaction with happiness, but they did find such an interaction with depression. They explain this by suggesting that depression is mostly related to chronic stressors, while well-being is more related to acute stressors. These acute stressors (transient life events) are more evenly distributed among urbanicity-race categories.

Amato and Zuo [30] report that it feels worse to be poor in a rural than an urban area. In addition, an urbanicity-race interaction effect on happiness was found. Poor African Americans seem to be happier (and less depressed!) in rural areas, while poor white Americans seem to be happier in urban areas. The authors explanation of this is that harsh inner-city living conditions are more important to poor blacks. They note that it is not surprising that poor African Americans experience a particularly low level of psychological well-being in urban areas. This population is concentrated in inner-city neighbourhoods characterized by substandard housing, inferior schools, high crime rates, poor services, and inadequate transportation. For the more dispersed poor white population, the rural environment has a detrimental influence on happiness because of stigmatization. However, this argument runs counter to Palisi's relative deprivation hypothesis, which maintains that urban blacks would be relatively happier than urban whites. Perhaps the reason for this contradiction is that Amato and Zuo's study concentrates on poor people and Palisi's does not.

Amato and Zuo's study shows that the relationships of urban-rural poverty also differ by family status and gender. Poor urban married women without children show high levels of well-being (and low depression scores) compared to their rural counterparts. The authors explain this quite tautologically by stating that poor urban women are better off with a husband, without the responsibility for children. On the other hand poor rural single men show relatively

Table 3. Urbanicity and well-being: main effects and interactions with urbanicity found in the literature

\begin{tabular}{|c|c|c|c|c|c|}
\hline Source & Country & Health measure & Model main effects & $\begin{array}{l}\text { Interaction urbanicity } \\
\text { with }\end{array}$ & $\begin{array}{l}\text { Mechanism behind } \\
\text { interaction effect }\end{array}$ \\
\hline [28] & GB & life satisfaction scale & $\begin{array}{l}\text { health status, social } \\
\text { activities, social net- } \\
\text { work variables }\end{array}$ & physical health status & $\begin{array}{l}\text { fewer open spaces, } \\
\text { multistorey } \\
\text { buildings in urban }\end{array}$ \\
\hline [19] & US & $\begin{array}{c}\text { well-being (Affect } \\
\text { Balance Scale) }\end{array}$ & $\begin{array}{l}\text { physical health, wealth, } \\
\text { education, marital } \\
\text { status, social network } \\
\text { variables, social activities }\end{array}$ & physical health & $\begin{array}{l}\text { public transport absent in } \\
\text { suburban }\end{array}$ \\
\hline [30] & US & $\begin{array}{l}\text { happiness } \\
\text { (one item scale) }\end{array}$ & $\begin{array}{l}\text { gender, race, } \\
\text { employment status, } \\
\text { family status, age, } \\
\text { education, family } \\
\text { income, urbanicity }\end{array}$ & race & ghettos relatively unhealthy \\
\hline [29] & US & happiness & $\begin{array}{l}\text { age, gender, race, } \\
\text { education, unemployment, } \\
\text { urbanicity }\end{array}$ & race & relative deprivation \\
\hline
\end{tabular}


low scores on well-being. Rural family orientation may have something to do with this phenomenon, leaving rural single men relatively isolated.

Also, the relation between health status and wellbeing seems to vary according to urbanicity. One study, carried out by Bowling et al. [28], reports that health status is a better predictor of life satisfaction in urban than in rural areas. Apparently, physical impairment has more serious consequences in urban than in rural areas. The authors suggest that poor health is a greater handicap for elderly people living in densely populated areas with many stairs to climb, higher traffic densities and fewer possibilities for relaxation in open spaces. On the other hand, retired suburban men with poor health in the U.S. have lower well-being than their urban and rural counterparts [19]. The authors suspect that the loss of physical mobility associated with poor health makes the use of automobiles more difficult and bridging distances more problematic. Differences between the U.S. and England in the availability of public transportation may account for these differing results. In the study by Bowling, a well developed semi-rural area with relatively good public transport was compared with a very densely populated area in London. The study by Reitzes concerned a national U.S. sample in which central city, suburban and nonmetropolitan areas were compared. Indeed public transport in general is not as readily available in the U.S. as a whole and especially not in suburban areas.

\section{Physical health}

Compared to the measures of well-being and mental health discussed above, it is much more difficult to conduct large scale population surveys on distinct physical health problems. The incidence or prevalence figures are often simply too low to allow this. Therefore, in this area of research, aggregate studies are more common and it does not make sense to limit ourselves to population based surveys. The exception is perhaps the area of self-assessed general physical health. This health measure will be discussed first, followed by five broad categories of disorders: cancer, respiratory diseases, musculoskeletal disorders, sexually transmitted diseases and cardiovascular diseases.

General physical health. General physical health is usually measured in terms of 'self assessed health' or 'functional ability'. Multivariate individual-based studies have found varying results. In some studies, taking into account confounding variables, higher urban morbidity is reported, and in other studies higher rural morbidity is found. For example, a Finnish study by Vuorinen et al. [31] reports a smaller number of restricted activity days in children on the periphery compared to children in the core area (but no difference in chronic diseases). In a Dutch study [32] urbanicity was regarded as an unimportant but not negligible factor compared to gender, marital status, and level of education. A British study based on the National Household Survey [33] revealed unexplained urban-rural variation in perceived health in a controlled study. On the other hand, Krout [34], adjusting for age, gender, race, living arrangement, marital status and several SES measures, did not find significant residential differences in health despondency and self-assessed health in elderly people. Also, in a sample of elderly in Finland no significant differences were found, controlling for gender [35]. In Northern England, the relationship between urbanicity and health at the ward level weakens when wealth is controlled for [36].

In conclusion, there seems to be a tendency towards better perceived health in rural areas, but this tendency disappears in many studies when controlling for demographic variables such as gender and age and enabling variables like socioeconomic status. We will enlarge upon these results below, paying additional attention to interaction effects.

Using a rather unusual combined urbanicity measure that includes population characteristics as well as characteristics of the physical environ-

Table 4. Urbanicity and physical health: main effects and interactions with urbanicity found in the literature

\begin{tabular}{|c|c|c|c|c|c|}
\hline Source & Country & Health measure & Model main effects & $\begin{array}{l}\text { Interaction urbanicity } \\
\text { with }\end{array}$ & $\begin{array}{l}\text { Mechanism behind } \\
\text { interaction effect }\end{array}$ \\
\hline [33] & UK & self reported morbidity & $\begin{array}{l}\text { age, gender, SES, } \\
\text { car availability, region, } \\
\text { socioeconomic ward } \\
\text { classification }\end{array}$ & gender* & not given \\
\hline [29] & US & self reported health & $\begin{array}{l}\text { age, gender, race, } \\
\text { education, unemployment, } \\
\text { neighbourhood fear, } \\
\text { urbanicity }\end{array}$ & socio-economic status & relative deprivation \\
\hline [37] & NL & perceived health & $\begin{array}{l}\text { age, gender, social contacts, } \\
\text { social participation, } \\
\text { marital status, SES, } \\
\text { medical consumption, } \\
\text { urbanicity }\end{array}$ & gender & not given \\
\hline
\end{tabular}

*For acute sickness only. 
ment, Haynes [33] reports lower age and gender standardized acute and chronic morbidity figures in high status wards (which are non-urban). An interaction effect was found where women in inner city areas are often confronted with acute sickness. The weakness of social supportive networks in inner city areas with transient populations is one example of a possible, previously ignored link with the perception of illness [33] (p. 366). Why this link would be particularly important to women remains unclear.

Also Perenboom et al. [37] found significant urban/rural differences in perceived health, especially for elderly women (as opposed to elderly men). Rural elderly rated their health better than urban elderly, rural elderly also have fewer problems with ADL, and there are no apparent explanations for differences between rural and urban elderly in income, social contacts, social participation, or availability of community care or medical consumption. This finding refutes the suggestion made by Haynes [33] that urban-rural differences may be explained away by taking account of social networks.

Another Dutch study, by Leeflang et al. [23] reports that the importance of variables in explaining somatic symptoms in unemployed people varies between rural and urban areas. Long duration of unemployment and financial problems are more detrimental to one's health in the urban area, while rural unemployed men suffer more from not having a partner. According to the authors, rural people are less tolerant of deviant behaviour.

An interaction effect between urbanicity and education was found by Palisi et al. [29] who found that lower educated people have slightly better health when they reside in an urban area. For higher educated people this rural-urban difference was absent. They found a similar interaction when looking at happiness and suggest a similar 'relative deprivation' hypothesis.

Cancer. Concerning urban-rural differences in the risk of cancer the literature is quite unequivocal. For most types of cancer higher incidence rates were found in urban areas. The models that are used to explain variations in cancer incidence usually include only age, gender, and place of residence. Interaction effects were seldom investigated, and one might well ask: would the results differ if other variables were included in the analysis?

Greenberg et al. [38] found higher incidence rates in urban black people in Georgia, adjusting for age and gender. Hoe et al. [39], using a four group categorization of urbanicity based on population density, found higher incidence rates of various types of cancer in urban counties, controlling for age, gender and race composition of these counties. This is consistent with Doll [40] who compared incidence rates of several types of cancer in several countries and found higher incidence rates in urban areas.

Interaction-effects were found between urbanicity and gender by Doll [40]. Urban excesses in the prevalence of cancer are more often observed in men than in women, and in men the urban-rural difference is larger, with almost no exception. This may be due to differences in the (etiology of the type of illness under study or the confounding factor of gender-related health habits like drinking and smoking.

There are other examples of gender/urbanicity interactions. Schouten et al. [41], controlling for age composition, found higher urban incidence rates for cancer in all sites in men but only cancers of the respiratory tract in women. A French study [42] on liver cancer found higher incidence rates in urban areas in men but no differences in women. Colorectal cancer in men also shows higher incidence rates in men in urban areas, while there is no such difference in women. An American study by Masca et al. [43] showed a higher urban excess in cancer incidence figures in males than in females. Similar results were found in Denmark [44].

There are some exceptions to the excess in urban cancer incidence generally found. Higher ageadjusted rural incidence rates were found for cancer of the oesophagus in men in France [44]. This was partly explained by regional differences in agricultural employment, level of education, and housing quality. This conclusion is, however, challenged by Doll [40] who found an excess incidence of cancer of the oesophagus among urban men.

Leukemia and Hodgkin's disease also seem to be exceptions to the rule of higher cancer incidence in urban areas. Alexander et al. $[45,46]$ found the highest incidence rates for both diseases among children in wards that were farthest away from urban centers with high socio-economic status. According to the authors urban-rural status functions as an inadequate proxy for isolation. Lifestyle in isolated communities is conducive to an unusual exposure to some specific infectious agent or to general infections, and this exposure in turn increases the risk of childhood leukaemia. Other exceptions are, according to Doll [40], cancers of the lip and eye, which are more common in rural areas. Confounding factors are, according to Doll, more pipe smoking and exposure to UV-light in rural areas.

Respiratory problems. Concerning respiratory problems the picture is again diffuse. In some studies a better health status was found in urban areas and in other studies in rural areas. The analytical models usually include age, gender, and-less oftensmoking habits.

A Swedish study and two studies in the U.S. come to the conclusion that asthma and chronic bronchitis are more prevalent in urban areas [47-50]. The same applies to allergic rhinitis in the U.S. [51] and COPD in Greece [52]. Higher levels of pollution are often thought to account for this difference. The possibility that the differences are due to migration is usually regarded as only marginal $[50,53]$. 
On the other hand, no urban-rural differences were observed in non-allergic nasal complaints in Sweden [54], in respiratory allergies in Austria [55], in COPD in the Netherlands [56], nor in the U.S. for age and smoking adjusted figures on chronic rhinitis, asthma, chronic bronchitis and chronic cough [51]. The only study in which interaction effects were explicitly investigated was by Spinaci et al. [57] but an effect of gender/geographic area on children's lung function was not found.

Musculoskeletal disorders. Literature on urbanrural differences in musculoskeletal disorders concentrates almost exclusively on hip fractures. Among the broad category of musculoskeletal disorders, hip fractures are the most popular when urban-rural comparisons are concerned. With some exceptions the studies were carried out in Scandinavian countries [58-63]. All studies showed significantly more hip fractures in urban areas. This difference is usually attributed to lower bone mineral content in urban areas and a higher tendency to fall [61]. Causes of hip fractures in urban areas more often concern traffic accidents [63], a finding that is consistent with Thouez et al. [64], who found higher urban incidence from non-severe car accidents.

Interaction-effects were found between urbanicity and gender, especially in elderly persons. Urban excess morbidity appeared most strongly in (elderly) women [63,65] as compared to elderly men.

Sexually transmitted diseases. Most sexually transmitted diseases are regarded as typically urban problems. In the case of AIDS and HIV infection, the major associations are substance abuse, prostitution, and prevalence of homosexuality. The literature also describes other modes of transmission [66]. Diffusion may be partly due to urban emigration of HIVinfected persons. Other sexually transmitted diseases that are linked to urbanicity include chlamydia infections [67], gonococcal infections [68], hepatitis B [69], cervical condylomas [70], and syphilis [70]. In all cases higher incidence rates were found in urban areas, but interaction effects were not explicitly investigated.

Circulatory system/cardiovascular diseases. Hypertension in young adults was investigated by Thomas and Groer [71]. High systolic blood pressure is associated with age, gender, body mass and urban residence. Urban residence was the strongest predictor of female systolic pressure. Hypertension in elderly people was studied by Weiler and Lubben [72]. They also found higher hypertension prevalence in urban areas. Finally, in a Swedish study among bus drivers, myocardial infarction was more common in urban areas. Interaction-effects were not explicitly investigated.

\section{SUMMARY AND CONCLUSIONS}

The central issue in this paper is the relation between individual and ecological variables in explaining health. Analyzing these relations has become more viable with the introduction of multilevel modelling techniques. The central question in this paper was: What is the role of the environment in explaining the health of individuals? The focus was on urbanicity as it is one of the most commonly used ecological variables in empirical research, while at the same time the mechanisms behind its impact are not well understood.

To explore the possible answers to this question a short introduction was given on possible reasons behind geographical disparities in health. The breeder hypothesis points to exposure and behaviour, while the drift hypothesis refers to movements of specific categories of people. It was subsequently concluded that it does not pay to focus on the drift hypothesis because studies in which the drift hypothesis could be investigated are very rare. Longitudinal data are needed but not available. It was decided that-in order to address our question by means of a reviewit was best to focus on the breeder hypothesis, controlling as much as possible for the compositional differences resulting from indirect selection effects. It was argued that interactions between aggregate and individual level deserve special attention. Living in a particular type of area (rural or urban) seems to be related to other demographic variables as they affect health. The impact of the environment may vary from person to person, or the impact of individual variables may vary from place to place. It will therefore only be possible to tease out the relevant health related aspects of urbanicity by investigating interaction effects. A summary of interaction effects that were found in the literature is given in Table 5. Caution should be used with interpreting the signs. They indicate only the relative position of urban vs rural residents in the same demographic or behavioural category.

Beginning with physical health, the most convincing interaction is between urbanicity and gender. Urban-rural health differences seem to be particularly prevalent in women. One author contended that this may be due to the presumed weakness of supportive networks in cities. This would imply, however, that social networks are more important for women's health than for men's health. This could not be corroborated with other literature. An alternative explanation for this is perhaps found in an article by Gabe and Williams [73]: if there are health differences that can be attributed to environmental differences, these health differences should be observable particularly in those groups that are most tied to the house and immediate neighbourhood: women.

Regarding stress-related variables such as unemployment, financial problems and low education (which stands for low SES) it must again be concluded that they are not only associated with urbanicity but that their influence also differs according to urbanicity of residence.

Regarding cancer we may conclude that most types are more common in urban areas, with the exception 
Table 5. Interaction effects found in the literature and their explanations

\begin{tabular}{|c|c|c|c|}
\hline Health problem & $\begin{array}{l}\text { Interaction } \\
\text { urbanicity with }\end{array}$ & Specification & Explanation \\
\hline Mental health & $\begin{array}{l}\text { race [17] } \\
\text { unemployment [22] } \\
\text { alcohol consumption [14] } \\
\text { age [16] } \\
\text { marital status [15] }\end{array}$ & $\begin{array}{l}\text { + black urban + } \\
\text { - black rural - } \\
\text { - urban men - } \\
\text { + rural men + } \\
\text { - urban drinkers - } \\
\text { + rural drinkers + } \\
\text { + elderly urban + - young urban - } \\
\text { - elderly rural - + young rural + } \\
\text { + urban divorced + } \\
\text { - rural divorced - }\end{array}$ & $\begin{array}{l}\text { learned helplessness } \\
\text { informal employment possibilities in } \\
\text { rural areas, social support } \\
\text { not given } \\
\text { social change } \\
\text { stigmatization/tolerance }\end{array}$ \\
\hline Well-being & $\begin{array}{l}\text { physical health status [28] } \\
\text { family status [30] } \\
\text { race [30] }\end{array}$ & $\begin{array}{l}\text { - bad ph. health urb. }- \\
+ \text { bad ph. health rur. }+ \\
+ \text { married no children urban }+ \\
\text { - married with children urban }- \\
\text { - poor black urb. }-\quad+\text { poor white urban }+ \\
+ \text { poor black rur. }+\quad \text { - poor white rural }-\end{array}$ & $\begin{array}{l}\text { constraints in physical environment } \\
\text { street violence, traffic } \\
\text { ghet tos relatively unhealthy }\end{array}$ \\
\hline Physical health & $\begin{array}{l}\text { gender }[33,37] \\
\text { not having a partner [23] } \\
\text { low education [29] }\end{array}$ & $\begin{array}{l}\text { - female urban - } \\
+ \text { female rural }+ \\
+ \text { single urban }+ \\
\text { - single rural - } \\
+ \text { low education urban }+ \\
\text { - low education rural - }\end{array}$ & $\begin{array}{l}\text { women higher exposure to unhealthy } \\
\text { citylife } \\
\text { stigmatization/tolerance } \\
\text { relative deprivation }\end{array}$ \\
\hline
\end{tabular}

Signs indicate the relative position of urban versus rural residents in the same (demographic or behavioural) category. + indicates better health status, - indicates worse health status.

of leukemia, Hodgkin's disease and possibly cancer of the oesophagus. Furthermore, for most types of cancer urban excess is typical of men. This is probably due to gender-differences in lifestyle. Much can be improved regarding the models that are used. A first step in the right direction is including more individual-based data. Including lifestyle characteristics is another step, though this is easier said than done: the time lag between, for instance, smoking and cancer is unknown. With regard to musculoskeletal disorders, urban morbidity is higher than rural morbidity as far as women are concerned. No explanation for this finding was offered. Concerning the circular system again urban excess morbidity was found, but interaction effects were nowhere explicitly investigated. The most important conclusion regarding the broad categories of physical disorders considered here must be that very little attention is paid to interaction effects and that especially in this field much remains to be done.

Regarding the relation between mental health and urbanicity the stress-hypothesis is most popular, contending that the urban environment is more stressful, leading to higher levels of mental disorder. Evidence is found by several authors in the fact that there is a direct effect of stress-indicating variables that are indeed associated with city life.

However, the frequent occurrence of interaction effects shows that this is too simple an explanation. Indeed we have seen that the impact of stress variables themselves varies according to urbanicity. In Table 5 there are two urban conditions that may prove to be important: stigmatization/tolerance and learned helplessness. Divorce can, for instance, be regarded as a stressor that is strongly associated with city life. At the same time, however, it is city life that offers better opportunities to cope with divorce via a higher tolerance and less stigmatization towards the unusual, as well as offering more opportunities to meet new partners, thereby limiting the negative health consequences of divorce. Another example of urban-rural differences in possibilities for coping with individual trouble is learned helplessness which is suggested to prevail among black rural residents and not in black urban residents and which counterbalances the fact that urban blacks tend to live in relatively unhealthy environments. Negative aspects of city life may be present in the stress resulting from social change and limited informal employment possibilities. The first would then explain a higher prevalence of mental problems in young city residents as compared to older city residents.

Similar conclusions may be drawn from looking at well-being: here too urbanicity moderates the relation between stressors and health. The evidence is rather convincing regarding physical health as a stressor. Physical health problems clearly constitute a meaning for well-being that differs from city to countryside. Factors that make living with a physical handicap more problematic, like stairclimbing or crossing busy roads, occur much more frequently in urban areas. Regarding race there is less agreement among authors. Race-urbanicity interactions are found but not consistently so. The distinction between chronic and acute stressors is important to remember, the hypothesis being that well-being is largely affected by acute stressors, while mental disorders are more associated with chronic stressors.

Regarding the three aspects of health two important conclusions can be drawn. First, based on the fact that very often bivariate analyses have shown an urban disadvantage regarding health, the 


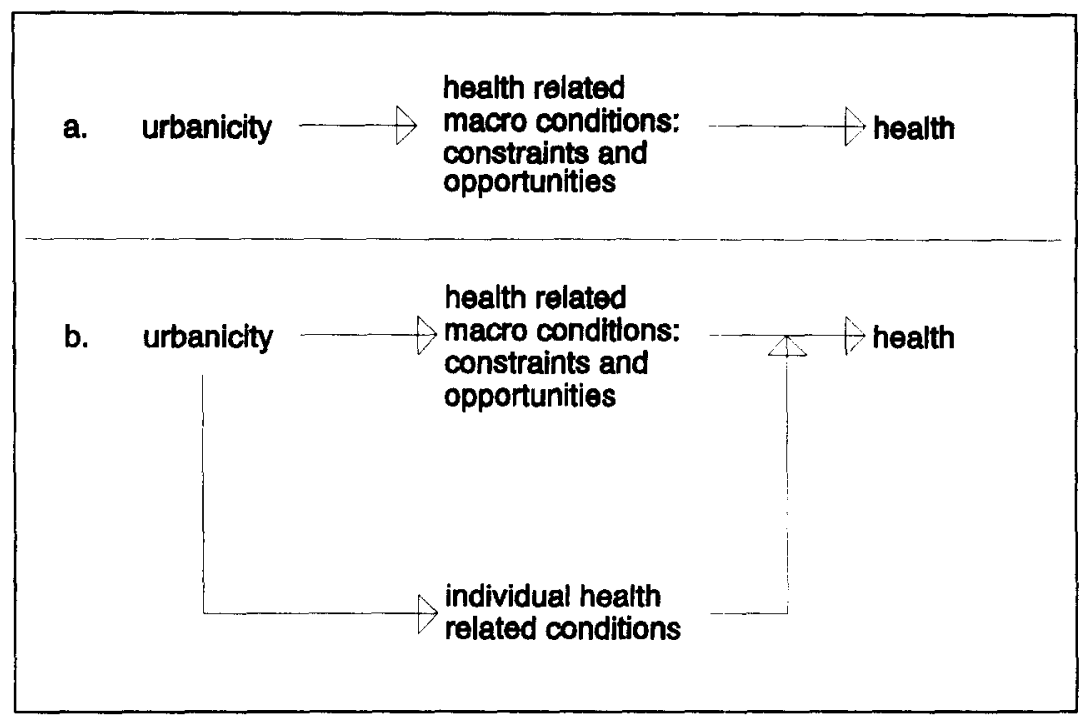

Fig. 1. Two simple explanatory models.

emphasis has been primarily on urban constraints instead of opportunities. Possibly combined with the 18 th century pastoral romanticist ideology regarding the purity and salutary qualities of rural societies the result has been an insufficient appreciation of the positive aspects of urban living. Second, it is important to note that these environmental constraints and opportunities have an effect on health that is in many cases dependent on the person who is living in that environment.

The extent to which the environment exerts its influence on a person's health is dependent on that person's individual characteristics. Much previous work on urban-rural differences has conceptualized this relation as depicted in Fig. 1(a). The current review, however, suggests to replace this by Fig. 1(b), in which interactions between the individual level and environment are more fully appreciated.

However, these conclusions are important only for further investigating the breeder hypothesis. In order to gain more insight into the drift hypothesis much more work remains to be done. A start can be made with gathering population based longitudinal data in which breeder and drift hypotheses can be examined together.

Acknowledgements - The author would like to thank Dinny de Bakker, Peter Groenewegen and Paulus Huigen for their comments on an earlier version of this paper. Paul ten Zijthoff should be mentioned for his valuable work gathering much of the literature. This study was supported by a grant from the Netherlands Organisation for Scientific Research.

\section{REFERENCES}

1. Jones K. Everywhere is Nowhere: Multilevel Perspectives on the Importance of Place. University of Portsmouth, Portsmouth, 1993.
2. World Bank. World Development Report 1993 Investing in Health. Oxford University Press, Oxford, 1993.

3. Tsouros A. D. (ed.) WHO healthy cities project a project becomes a movement. Review of Progress 198710 1990. FADL publishers, Copenhagen, 1991.

4. Hancock T. The healthy city from concept to application. In Healthy Cities. Research and Practice (Edited by Davies J. K. and Kelly M.), p. 14-24. Routledge. London, 1993.

5. Hoggart K. Let's do away with rural. J. Rural Stud. 6 , $245,1990$.

6. Webb L. Rural-urban differences in mental disorder In Mental Health and the Environment (Edited by Freeman H.). Livingstone-Churchill, London, 1984.

7. Marsella A. J. Urbanization and mental disorders: an overview of theory and research, and recommendations for interventions and research. WHO, Geneva, 1990 (unpub).

8. Harpham T. Urbanization and mental health in developing countries: a research role for social scientists, public health professionals and social psychiatrists. Soc. Sci. Med. 39, 233, 1994.

9. Blazer D.. George L. K., Landerman R. et al. Psychiatric disorders. A rural/urban comparison. Arch Gen. Psychiat. 42, 1142, 1985.

10. Jones K. and Moon G. Health, Disease and Society An introduction to Medical Geography. Routledge \& Kegan Paul, London, 1987.

11. Lewis G., David A., Andreasson S. and Allebeck P. Schizophrenia and city life. Lancet 340, 137, 1992.

12. Garretsen H. F. L. and Raat H. Urban health in the Netherlands: health situation, health care facilities an public health policy. Hith Policy 18, 159, 1991.

13. Jones K., Duncan C. and Moon G. Individuals and their ecologies: analysing the geography of chronic illness within a multilevel modelling framework. Paper presented at the 6th International Medical Geography Symposium, 1994.

14. Neff J. A. and Husaini B. A. Stress-Buffer Properties of Alcohol Consumption: The Role of Urbanicity and Religious Identification. J. Hlth Soc. Behav. 26, 207, 1985.

15. Romans-Clarkson S. E., Walton V. A., Herbison G. P. and Mullen P. E. Psychiatric morbidity among women in urban and rural New Zealand: psycho-social correlates. Br. J. Psychiat. 156, 1990. 
16. Crowell B. A., George L. K., Blazer D. and Landerman R. Psychosocial risk factors and urban/rural differences in the prevalence of major depression. Br. J. Psychiat. 149, 307, 1986.

17. Neff J. A. and Husaini B. A. Urbanicity, race, and psychological distress. J. Commun. Psychol. 15, 520, 1987.

18. Joukamaa M, Saarijärvi S. and Salokangas R. K. The TURVA project: retirement and adaptation in old age. Zeit. Geront. 26, 170, 1993.

19. Reitzes D. C., Mutran E. and Pope H. Location and well-being among retired men. J. Geront. Soc. Sci. 46, S195, 1991.

20. Larsson B. and Melin L. Prevalence and short-term stability of depressive symptoms in schoolchildren. Acta Psychiat. Scand. 85, 17, 1992.

21. Dohrenwend B. P. and Dohrenwend B. S. Psychiatric disorders in urban settings. In American Handbook Psychiatry, 2nd Edition, Vol. 2 (Edited by Arieti S. and Caplan S.). Basic Books, New York, 1974.

22. Harding L. and Sewel J. Psychological health and employment status in an island community. J. Occ. Organ. Psychol. 65, 269, 1992.

23. Leeflang R. L. I., Klein-Hesselink D. J. and Spruit I. Health effects of unemployment-I. Long-term unemployed men in a rural and an urban setting. Soc. Sci. Med. 34, 341, 1992

24. Tousignant $M$. and Kovess V. Borderline traits among community alcoholics and problem-drinkers: rural urban differences. Can. J. Psychiat. 34, 796. 1989.

25. Swartz M., Landerman R., Blazer D. and George L. Somatization symptoms in the community: A rural/ urban comparison. Psychosomatics 30, 44, 1989.

26. Carpiniello B., Carta M. G. and Rudas N. Depression among elderly people: a psychosocial study of urban and rural populations. Acta Psychiat. Scand. 80, 445, 1989

27. Bigbee J. L. Stressful life events and illness occurrence in rural versus urban women. J. Commun. Hlth Nurs. 7 , $105,1990$.

28. Bowling A., Farquhar M. and Browne P. Life satisfaction and associations with social network and support variables in three samples of elderly people. Int. J. Geriatric Psychiat. 6, 549, 1991.

29. Palisi B. J., Ransford H. E. and Pampalon R. Effects of urbanism, race, and class on happiness and physical health. Soc. Spectrum 7, 253, 1986.

30. Amato P. R. and Zuo J. Rural poverty, urban poverty, and psychological well-being. Sociol. $Q .33$, $229,1992$.

31. Vuorinen H. S., Mäkelä M., Tuomikoski H. and Floman P. Core-periphery differences in children's health and use of general practitioner services in Finland from 1964 to 1987. Soc. Sci. Med. 33, 1023, 1991

32. Mackenbach J. P. Inequalities in health in The Netherlands according to age, gender, marital status, level of education, degree of urbanization, and region. Eur. J. Publ. Hlth 3, 112, 1993

33. Haynes R. Inequalities in health and health service use: evidence from the General Household Survey. Soc. Sci. Med. 33, 361, 1991.

34. Krout J. A. Rural versus urban differences in health dependence among the elderly population. International J. Aging Hum. Dev. 28, 141, 1989.

35. Matilla V., Joukamaa M. and Salokangas R. K. Mental health in the population approaching retirement age in relation to physical health, functional ability and creativity: Findings of the TURVA project. Acta Psychiat. Scand. 77, 42, 1988.

36. Phillimore P. and Reading R. A rural advantage? Urban-rural health differences in Northern England. J. Publ. Hlth Med. 14, 290, 1992.
37. Perenboom R. J., Lako C. J. and Schouten E. G. Health status and medical consumption of rural and urban elderly. Comp. Geront. Section B, Behav. Soc. Appl. Sci 2, 124, 1988.

38. Greenberg R. S., Stevens J. A. and Whitaker J. Cancer incidence rates among blacks in urban and rural Georgia, 1978-82. Am. J. Publ. Hlth 75, 683, 1985.

39. Howe H. L., Keller J. E. and Lehnherr M. Relation between population density and cancer incidence, Illinois, 1986-90. Am. J. Epidemiol. 138, Monotonic, 1993.

40. Doll Sir R. Urban and rural factors in the aetiology of cancer. Int. J. Cancer 47, 803, 1991

41. Schouten L. J., Kiemeney L. A. L. M., Verbeek A. L. M. and Brandt P. A. vd. Stad-platteland verschillen in kankerincidentie in Midden- en Zuid-Limburg. Tijdschrift Soc. Gezondheidszorg 69, 345, 1991.

42. Boutron M. C., Faivre J., Milan C., Bedenne L., Hillon P. and Klepping C. Primary liver cancer in Côte d'Or (France). Int. J. Epidemiol. 17, Cirrhosis, 1988.

43. Bremond A., Mamelle N., Laumon B. and Aknin D. Dépistage des condylomes plans du col utérin dans le département du Rhône. Revi. d'Epidémiol. Santé Publique 36, 209, 1988.

44. Frisch M., Melbye M. and Møller H. Trends in incidence of anal cancer in Denmark. Br. Med.J. 306, 419 , 1993

45. Alexander F. E., Ricketts T. J., Mckinney P. A. and Cartwright R. A. Community lifestyle characteristics and incidence of Hodgkin's disease in young people Int. J. Cancer 48, 10, 1991 .

46. Alexander F. E., Ricketts T. J., Mckinney P. A. and Cartwright R. A. Community lifestyle characteristics and risk of acute lymphoblastic leukaemia in children. Lancet 336, 1461, 1990.

47. Lundbäck B., Nyström L., Rosenhall L. and Stjernberg N. Obstructive lung disease in northern Sweden respiratory symptoms assessed in a postal survey. Eur. Resp. J. 4, 257, 1991.

48. Gergen P. J., Mullally D. I. and Evans R. National survey of prevalence of asthma among children in the United States, 1976 to 1980. Pediatrics 81, 1, 1988.

49. Gerstman B. B., Bosco L. A., Tomita D. K., Gross T. P. and Shaw M. M. Prevalence and treatment of asthma in the Michigan Medicaid patient population younger than 45 years, 1980-1986. J. Allergy Clin. Immunol. 83, 1032, 1989.

50. Heinonen O. P., Horsmanheimo M., Vohlonen I. and Terho E. O. Prevalence of allergic symptoms in rural and urban populations. Eur. J. Resp. Dis. (Suppl.) 152, 64, 1987.

51. Turkeltaub P. C. and Gergen P. J. Prevalence of upper and lower respiratory conditions in the US population by social and environmental factors: data from the second National Health and Nutrition Examination Survey, 1976 to 1980 (NHANES II). Ann. Allergy 67, 147, 1991

52. Tzonou A., Maragoudakis G., Trichopoulos D et al. Urban living, tobacco smoking, and chronic obstructive pulmonary disease: a study in Athens. Epidemiology 3, 57, 1992.

53. Viegi G., Paoletti P., Carrozzi L et al. Prevalence rates of respiratory symptoms in Italian general population samples exposed to different levels of air pollution. Environ. Hith Perspect. 94, 95, 1991.

54. Jessen M. and Janzon L. Prevalence of non-allergic nasal complaints in an urban and a rural population in Sweden. Allergy 44, 582, 1989.

55. Popp W., Swick H., Steyrer K, Rauscher H. and Wanke T. Sensitization to aeroallergens depends on environmental factors. Allergy 44, 572, 1989.

56. Rijcken B., Schouten J. P., Weiss S. T., Speizer F. E. and Lende $R$. van der. The relationship of nonspecific 
bronchial responsiveness to respiratory symptoms in a random population sample. Am. Rev. Resp. Dis. 136, 62, 1987.

57. Spinaci S., Arossa W., Bugiani M., Natale P., Bucca C. and Candussio G. D. The effects of air pollution on the respiratory health of children: a cross-sectional study. Pediat. Pulmonol. 1, 262, 1985.

58. Baudoin C., Fardellone P., Potard V. and Sebert J. L. Fractures of the proximal femur in Picardy, France, in 1987. Osteoporosis Int. 3, 43, 1993.

59. Finsen V. and Benum P. Changing incidence of hip fracture in rural and urban areas of central Norway. Clin. Orthopaed. Related Res. 218, 104, 1987.

60. Mannius S., Mellström D., Odén A., Rudgren A. and Zatterberg C. Incidence of hip fracture in Western Sweden 1974-1982: Comparison of rural and urban populations. Acta Orthopaed. Scand. 58, 38, 1987.

61. Jonsson B., Gardsell P., Johnell O., Redlund-johnell I. and Sernbo I. Differences in fracture pattern between an urban and a rural population: a comparative population-based study in southern Sweden. Osteoporosis Int. 2, 269, 1992.

62. Larsson S., Eliasson P. and Hansson L.-I. Hip fractures in northern Sweden 1973-1984. A comparison of rural and urban populations. Acta Orthopaed. Scand. 60, 567, 1989.

63. Sernbo I., Johnell O. and Andersson T. Differences in the incidence of hip fracture. Comparison of an urban and a rural population in southern Sweden. Acta Orthopaed. Scand. 59, 382, 1988.

64. Thouez J.-P., Joly M.-F., Rannou A., Bussière Y. and Bourbeau R. Geographical variations of motor-vehicle injuries in Quebec, 1983-1988. Soc. Sci. Med. 33, 415 1991.

65. Madhok R., Melton L. J., Atkinson E. J., O'Fallon W. M. and Lewallen D. G. Urban vs rural increase in hip fracture incidence. Age and sex of 901 cases 1980-89 in Olmsted County, U.S.A. Acta Orthopaed. Scand. 64(5), 543, 1993.

66. Karon J. M. and Berkelman R. L. The geographic and ethnic diversity of AIDS incidence trends in homosexual/bisexual men in the United States. J. AIDS 4 , 1179, 1991

67. Winter L., Goldy A. S. and Baer C. Prevalence and epidemiologic correlates of chlamydia trachomatis in rural and urban populations. Sex. Trans. Dis. 17, 30 1990.

68. Desenclos J.-C. A., Garrity D. and Wroten J. Pediatric gonococcal infection, Florida, 1984 to $1988 . \mathrm{Am} . \mathrm{J} . \mathrm{Pbl}$ Hith. 82, 426, 1992.

69. Salleras L., Bruguera M., Vidal J. et al. Prevalence of hepatitis B markers in the population of Catalonia (Spain). Rationale for universal vaccination of adolescents. Eur. J. Epidemiol. 8, 640, 1992.

70. Lee C. B., Brunham R. C., Sherman E. and Harding G. K. M. Epidemiology of an outbreak of infectious syphilis in Manitoba. Am. J. Epidemiol. 125, 277, 1987

71. Thomas S. P. and Groer M. W. Relationship of demographic, life-style, and stress variables to blood pressure in adolescents. Nursing Res. 35, 169, 1986.

72. Weiler P. G., Lubben J. E. and Chi I. Hypertension in elderly people in a preventive health program. $A m$. J. Prevent. Med. 5, 216, 1989.

73. Gabe J. and Williams P. Women, housing, and mental health. Int. J. Hlth Serv. 17, 667, 1987. 